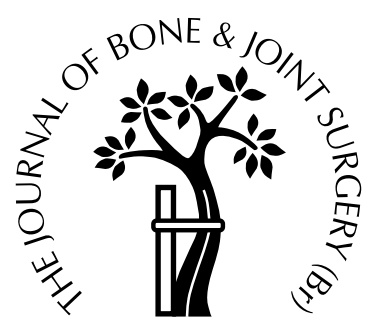

\title{
Reduction of blood loss using high-dose aprotinin in major orthopaedic surgery
}

\section{A PROSPECTIVE, DOUBLE-BLIND, RANDOMISED AND PLACEBO- CONTROLLED STUDY}

\author{
R. Jeserschek, H. Clar, C. Aigner, P. Rehak, B. Primus, R. Windhager \\ From the Karl-Franzens University School of Medicine, Graz, Austria
}

W e have investigated in a prospective, randomised placebo-controlled study the effect of high-dose aprotinin on blood loss in patients admitted for major surgery (revision arthroplasty of the hip or knee, or for resection of a soft-tissue sarcoma). The mean intraoperative blood loss was reduced from $1957 \mathrm{ml}$ in the control group to $736 \mathrm{ml}$ in the aprotinin group (p= $0.002)$. The mean requirement for intraoperative homologous blood transfusion in the aprotinin group was 1.4 units (95\% CI 0.2 to 2.7$)$ and 3.1 units $(95 \%$ CI 1.7 to 4.6$)$ in the control group $(p=0.033)$. The mean length of hospital stay was reduced from 27.8 days in the control group to $\mathbf{1 7 . 6}$ days in the aprotinin group which was not statistically significant.

The intraoperative use of aprotinin in major orthopaedic operations significantly reduced blood loss and the required amount of packed cells. It may result in a decrease in the length of hospital stay and costs.

J Bone Joint Surg [Br] 2003;85-B:174-7.

Submitted: 4 March 2002; Accepted: 17 July 2002

Aprotinin, a basic polypeptide (58 amino-acid residues) and serine protease inhibitor (plasmin, trypsin and kallikrein), was first isolated and described by Kraut ${ }^{1}$ and Kunitz. ${ }^{2}$ In 1959 it was approved for use in the treatment of pancreatitis

R. Jeserschek, MD, Consultant Orthopaedic Surgeon

H. Clar, MD, Research Assistant

C. Aigner, MD, Consultant Orthopaedic Surgeon

R. Windhager, MD, Professor and Chairman

Department of Orthopaedics

P. Rehak, PhD, Associate Professor

Department of Surgery, Division of Biomedical Engineering and Computing

B. Primus, PhD, Head of Pharmacy Department

University School of Medicine, Auenbruggerplatz 29, AT-8036 Graz, Austria.

Correspondence should be sent to Professor R. Windhager.

(C)2003 British Editorial Society of Bone and Joint Surgery doi.10.1302/0301-620X.85B2.13303\$2.00 and severe head injury. Royston, ${ }^{3}$ Royston et $\mathrm{al}^{4}$ and Lemmer et al $^{5}$ described the reduction of blood loss in cardiac surgery and its efficacy and safety. Further studies have demonstrated its effect in reducing blood loss in liver resection, spinal surgery and bilateral or revision arthroplasty of the hip. ${ }^{6-9}$ In unilateral primary arthroplasty of the hip, however, the indications for its use have been questioned and there have been concerns about side-effects such as immunological sensitisation and anaphylactic reactions, and the lack of a statistically proven effect on blood loss. ${ }^{10-12}$ Langdown et al $^{12}$ used a regimen with a single bolus of 1.5.x $10^{6}$ kallikrein inactivation units (KIU) of aprotinin and Kaspar et al $^{11}$ used a small-dose regimen with $20000 \mathrm{KIU}$ $\mathrm{kg}^{-1}$ after induction of anaesthesia. They reported low blood loss without significant difference between the study and the placebo groups. Wollinsky et $\mathrm{al}^{13}$ and Utada et al, ${ }^{14}$ however, described a statistically significant difference in the postoperative, but not the intraoperative blood loss.

There is no evidence that deep-vein thrombosis (DVT) is more common in those patients who receive aprotinin and in the study of Janssens et al ${ }^{15}$ more DVTs were detected in the placebo group, but the difference did not reach statistical difference.

We have carried out a prospective randomised study on 18 patients in order to assess the effect of aprotinin on blood loss and transfusion requirements in major orthopaedic operations with an expected high blood loss.

\section{Patients and Methods}

After approval by the Ethics Committee of the University of Graz the number of patients necessary for a statistically significant result was estimated. Randomisation was performed by the head of the pharmacy department (BP). All patients gave informed consent. Every operation was undertaken by one of three senior orthopaedic surgeons (RW, RJ, CA). The surgeons and anaesthetists were blinded as to whether the patients were receiving aprotinin or the placebo. A total of 18 consecutive patients with either aseptic or septic failure of a hip or knee prosthesis or undergoing resection of a softtissue sarcoma, was enrolled in the study. The exclusion criteria were known or suspected allergy to aprotinin or previous treatment with the drug. Details of the patients in both groups are given in Table I. The mean age of the aprotinin 
Table I. Details of the patients and intraoperative, postoperative and total blood loss (ml) and amount of transfused RBC (units) in the aprotinin and placebo groups

\begin{tabular}{|c|c|c|c|c|c|c|c|c|c|}
\hline \multirow[b]{2}{*}{ Case } & \multirow[b]{2}{*}{ Gender } & \multirow[b]{2}{*}{$\begin{array}{l}\text { Age } \\
\text { (yrs) }\end{array}$} & \multirow[b]{2}{*}{ Diagnosis } & \multicolumn{2}{|c|}{ Intraoperative } & \multicolumn{2}{|c|}{ Postoperative } & \multicolumn{2}{|l|}{ Total } \\
\hline & & & & $\begin{array}{l}\text { Blood } \\
\text { loss }\end{array}$ & $\begin{array}{l}\mathrm{RBC} \\
\text { transfused }\end{array}$ & $\begin{array}{l}\text { Blood } \\
\text { loss }\end{array}$ & $\begin{array}{l}\mathrm{RBC} \\
\text { transfused }\end{array}$ & $\begin{array}{l}\text { Blood } \\
\text { loss }\end{array}$ & $\begin{array}{l}\mathrm{RBC} \\
\text { transfused }\end{array}$ \\
\hline \multicolumn{10}{|c|}{ Aprotinin } \\
\hline 1 & $\mathrm{~F}$ & 65 & Revision arthroplasty & 531 & 0 & 310 & 0 & 841 & 0 \\
\hline 3 & $\mathrm{~F}$ & 65 & Revision THR & 954 & 0 & 630 & 0 & 1584 & 0 \\
\hline 4 & M & 45 & Revision THR & 2538 & 4 & 1430 & 2 & 3968 & 6 \\
\hline 5 & $\mathrm{~F}$ & 87 & Revision THR & 600 & 2 & 980 & 1 & 1580 & 3 \\
\hline 6 & $\mathrm{~F}$ & 74 & Revision TKR & 1305 & 1 & 1610 & 4 & 2915 & 5 \\
\hline 10 & $\mathrm{~F}$ & 72 & Revision THR & 246 & 0 & 10 & 2 & 256 & 2 \\
\hline 12 & $\mathrm{~F}$ & 75 & Revision THR & 500 & 2 & 325 & 2 & 825 & 4 \\
\hline 15 & M & 64 & Resection of soft-tissue sarcoma & 724 & 4 & 1640 & 0 & 2364 & 4 \\
\hline 17 & M & 56 & Revision THR & 709 & 0 & 900 & 2 & 1609 & 2 \\
\hline \multicolumn{10}{|c|}{ Placebo } \\
\hline 2 & $\mathrm{~F}$ & 62 & Resection of soft-tissue sarcoma & 679 & 0 & 850 & 1 & 1529 & 1 \\
\hline 7 & $\mathrm{~F}$ & 76 & Revision THR & 5550 & 5 & 650 & 3 & 6200 & 8 \\
\hline 8 & M & 60 & Revision THR & 1765 & 5 & 2735 & 5 & 4500 & 10 \\
\hline 9 & M & 72 & Revision TKR & 1997 & 4 & 830 & 2 & 2827 & 6 \\
\hline 11 & M & 72 & Revision THR & 3170 & 4 & 580 & 0 & 3750 & 4 \\
\hline 13 & $\mathrm{~F}$ & 81 & Revision THR & 1710 & 4 & 350 & 0 & 2060 & 4 \\
\hline 14 & $\mathrm{~F}$ & 79 & Revision THR & 1500 & 3 & 1810 & 2 & 3310 & 5 \\
\hline 16 & M & 71 & Revision THR & 1257 & 0 & 2750 & 0 & 4007 & 0 \\
\hline 18 & M & 82 & Revision THR & 3107 & 3 & 1150 & 1 & 4257 & 4 \\
\hline
\end{tabular}

group was 67 years (95\% CI 58 to 76) and of the control group 73 years (95\% CI 67 to 79$)$. The mean duration of surgery was 251 minutes (95\% CI 190 to 312 ) and 312 minutes (95\% CI 222 to 403$)$, respectively.

In order to exclude hypersensitivity reactions patients received either a testing dose of $10000 \mathrm{KIU}$ before the operation or the same volume of normal saline according to their random selection. At the beginning of the operation the patients received either $1 \times 10^{6} \mathrm{KIU}$ of aprotinin as a loading dose followed by continuous infusion of $500000 \mathrm{KIU} /$ hour, or the same volume of normal saline. The intraoperative blood loss was measured using a blood cell saver and by weighing the swabs. The postoperative blood loss was measured by suction drain bottles. The intraoperative transfusion of red blood cells (RBC) depended on the estimation of the blood loss by the anaesthetist. Confirmation was obtained in blood samples at the end of the operation in which the haematrocrit, haemoglobin and red blood cell and platelet counts were determined. All patients received the equivalent of 5000 units of low-molecular-weight heparin 12 hours before surgery and then daily until discharge from hospital and all received antibiotics according to the sensitivity of the organisms cultured in cases of septic failure of a prosthesis, or cefuroxime (1.5 g three times daily). Mobilisation was usually started on the second postoperative day. The suction drains were removed between two and four days after operation and blood samples were taken for the determination of haemoglobin, haematrocrit, red blood cell and platelet counts. The primary endpoint of the investigation was the intraoperative blood loss. Secondary endpoints were the postoperative and the total blood loss, the length of stay in hospital, the duration of intensive care and the requirement of homologous blood transfusion.

Statistical analysis. The sample size was estimated using information from a previous study. ${ }^{6}$ The geometric means of the intraoperative blood loss were estimated to be 1100 $\mathrm{ml}(\log 7.0)$ in the aprotinin group and $3000 \mathrm{ml}(\log 8.0)$ in the placebo group, with a standard deviation $(\log )$ of 0.6 . Given these assumptions a sample size of nine patients per group is sufficient to detect this difference at a significance level of 0.05 with a power of $95 \%$ (one-tailed two-sample $t$ test on the log-transformed data). One-sided testing was justified because there is no evidence of a possible negative effect of aprotinin on the endpoints and therefore no increased blood loss in the aprotinin group was to be expected. The blood loss data were log-normally distributed and analysed after log-transformation and presented as geometric means with $95 \%$ confidence intervals (CI). Comparisons between the two groups were drawn using two-sample $t$-tests. A one- sided alpha of 0.05 was considered to be significant. Only the primary endpoint, i.e. the intraoperative blood loss, was tested on a confirmatory basis; all other tests were exploratory. Thus no adjustment for multiple testing was done.

\section{Results}

The mean intraoperative blood loss was significantly lower $(\mathrm{p}=0.002)$ in the aprotinin group $(736 \mathrm{ml} ; 95 \% \mathrm{CI} 445$ to 1218) compared with the control group ( $1957 \mathrm{ml}$; $95 \% \mathrm{CI}$ 1227 to 3122 ) (Fig. 1). The ratio between these means is 2.7 (95\% CI 1.4 to 5.0). The mean postoperative blood loss was 


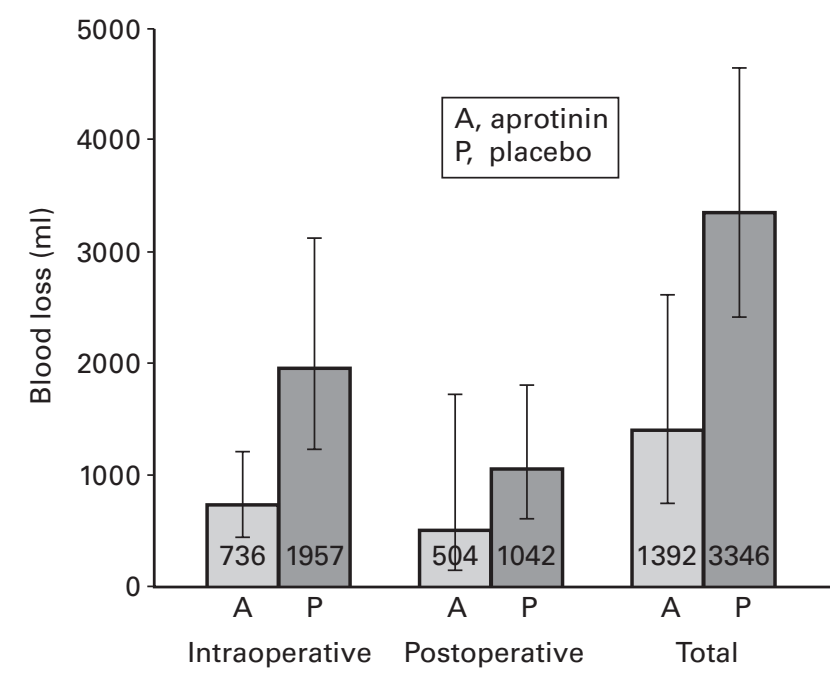

Fig. 1

The mean (95\% CI) intraoperative, postoperative and total blood loss in the aprotinin and control groups.

Table II. The mean preoperative, postoperative and two-to-four day haematocrit, red cell count, haemoglobin levels and platelet counts for both groups

\begin{tabular}{|c|c|c|}
\hline & Aprotinin & Placebo \\
\hline \multicolumn{3}{|l|}{ Haematocrit (\%) } \\
\hline Preop & 37.4 (34.0 to 40.7$)$ & 39.8 (35.8 to 43.7$)$ \\
\hline Postop & 29.2 (26.2 to 32.2$)$ & $29.8(26.2$ to 33.4$)$ \\
\hline Days 2 to 4 & $30.9(28.9$ to 32.8$)$ & $30.9(29.1$ to 32.7$)$ \\
\hline \multicolumn{3}{|c|}{ Red cell count $\left(\mathrm{x} 10^{12} / 1\right)$} \\
\hline Preop & $4.2(3.8$ to 4.6$)$ & $4.6(4.2$ to 5.0$)$ \\
\hline Postop & $3.3(2.9$ to 3.6$)$ & $3.4(3.0$ to 3.8$)$ \\
\hline Days 2 to 4 & $3.3(2.9$ to 3.6$)$ & $3.4(3.2$ to 3.6$)$ \\
\hline \multicolumn{3}{|c|}{ Haemoglobin (g/dl) } \\
\hline Preop & $12.7(11.4$ to 14.0$)$ & 13.4 (11.9 to 14.8$)$ \\
\hline Postop & $9.9(8.8$ to 11.0$)$ & $10.3(9.2$ to 11.5$)$ \\
\hline Days 2 to 4 & $10.0(8.8$ to 11.1$)$ & 10.5 (9.8 to 11.2$)$ \\
\hline \multicolumn{3}{|c|}{ Platelets (x 1000/dl) } \\
\hline Preop & 272 (193 to 352$)$ & $220(156$ to 285$)$ \\
\hline Postop & 207 (171 to 243$)$ & $164(132$ to 195$)$ \\
\hline Days 2 to 4 & 227 (187 to 268$)$ & $171(142$ to 201$)$ \\
\hline
\end{tabular}

$504 \mathrm{ml}$ (95\% CI 148 to 1724) in the aprotinin group and $1043 \mathrm{ml}$ (95\% CI 604 to 1800) in the control group, indicating a reduction by $50 \%$ (ratio $2.1 ; 95 \%$ CI 0.6 to 7.1 ) (Fig. $1)$. This difference, however, was not significant $(\mathrm{p}=0.115)$. The details of the individual patients are given in Table I.

The transfusion requirements (quantity) and the number of patients receiving transfusions in each group were smaller in the aprotinin group than in the control group. In the aprotinin group seven patients required 26 RBC units whereas in the control group eight required $42 \mathrm{RBC}$ units. This was mainly during the intraoperative period when five patients in the aprotinin group required only $13 \mathrm{RBC}$ units

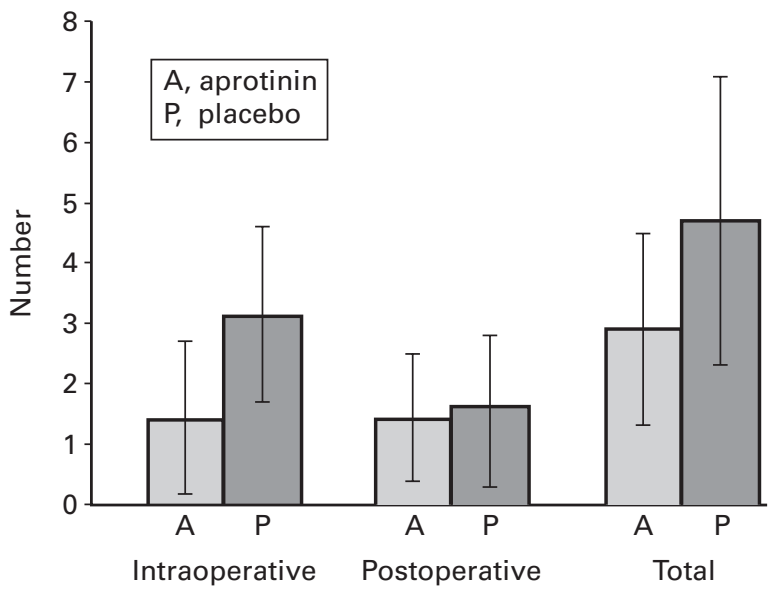

Fig. 2

The mean $(95 \% \mathrm{CI})$ number of intraoperative, postoperative and total requirement of packed red blood units.

compared with seven in the control group, who needed 28 units of packed red blood cells.

The mean amount of intraoperative blood transfused was significantly different $(\mathrm{p}=0.033)$; the aprotinin group received 1.4 units (95\% CI 0.2 to 2.7) and the control group 3.1 units (95\% CI 1.7 to 4.6 ) in order to maintain normal values of serum parameters during the operation (Table I and Fig. 2). After operation, the aprotinin group received 1.4 units (95\% CI 0.4 to 2.5 ) and the control group 1.6 units (95\% CI 0.3 to 2.8). The mean total volume of blood transfused per patient in the aprotinin group was 2.9 units (95\% CI 1.3 to 4.5 ) compared with 4.7 units $(95 \%$ CI 2.3 to 7.1$)$ in the control group $(\mathrm{p}=0.088)$. The difference (1.8 units) reflected the low rate of transfusion during surgery; the difference after operation was only 0.2 units less for the aprotinin group (Table I). There were no significant differences between the two groups regarding haematocrit, haemoglobin, or red cell and platelet counts, either during or after surgery (Table II).

No clinical signs of DVT were observed in either group between the date of surgery and review at three months. The mean length of hospital stay in the aprotinin group was 17.6 days (95\% CI 12.5 to 22.6 ) compared with 27.8 days (95\% CI 14.2 to 41.3) in the control group ( $\mathrm{p}=0.066)$. The mean duration of stay in intensive care was significantly less in the aprotinin group; 0.7 days compared with 1.6 in the control group $(\mathrm{p}=0.040)$.

Subgroup analysis revealed that if the two patients (one in each group) who had resection of a soft-tissue sarcoma were not included, the differences between the two groups became greater. The mean intraoperative need for blood was 1.1 units (95\% CI 0.9 to 2.3 ) in the aprotinin group and 3.5 (95\% CI 2.2 to 4.8 ) units in the control group, which is a mean difference of 2.4 units $(p=0.004)$. The postoperative 
need for blood was 1.6 units in both groups. The mean intraoperative blood loss was $738 \mathrm{ml}$ (95\% CI 411 to 1324) in the aprotinin group and $2234 \mathrm{ml}(95 \%$ CI 1482 to 3369) in the control group $(\mathrm{p}=0.001)$. The mean postoperative blood loss was $435 \mathrm{ml}$ (95\% CI 110 to 1719) and $1070 \mathrm{ml}(95 \%$ CI 569 to 2011) in the aprotinin group and in the control group, respectively $(\mathrm{p}=0.090)$.

\section{Discussion}

In this prospective randomised, double-blind and placebocontrolled study, we have shown that aprotinin decreases the blood loss and transfusion requirement in major orthopaedic operations. The main advantages were the reduction by $70 \%$ of the intraoperative blood loss $(p=0.002)$, the reduction by almost two units of packed red cells transfused intraoperatively $(\mathrm{p}=0.033)$ and a shorter stay in intensive care. A subgroup analysis excluding the two patients who had resection of soft-tissue sarcoma, gave the same results; the differences between the groups were, if anything, more pronounced.

In previous studies, the effect of aprotinin on primary hip surgery has seemed to be inconsistent, ${ }^{12,15-17}$ but in major orthopaedic surgery two studies showed a decrease in blood loss and the requirement for transfusion. ${ }^{6,7}$ There was no difference in blood loss between a set dose ${ }^{6}$ or a dose-toweight regimen ${ }^{7}$ which implies that the efficacy of aprotinin may be achieved through the simpler set-dose method. The different loading dose of $1 \times 10^{6}$ or $2 \times 10^{6} \mathrm{KIU}$ of aprotinin did not give any difference in blood loss or required replacement. A similar finding was seen in our study, in which $1 \mathrm{x}$ $10^{6} \mathrm{KIU}$ was given as a bolus, to that of Murkin et $\mathrm{al}^{7}$ in which $2 \times 10^{6} \mathrm{KIU}$ were given. There were no clinical signs of DVT during the follow-up period of three months. With reference to the studies of Murkin et al ${ }^{7,16}$ and Capdevila et al, ${ }^{6}$ which did not show any increase in the incidence of DVT in the aprotinin group, we did not undertake venography on our patients.

The shorter period of time spent in hospital did not reach significance $(\mathrm{p}=0.066)$, but indicated a trend. The patients in the aprotinin group, however, stayed in intensive care almost one day less $(\mathrm{p}=0.040)$.

Cost-effectiveness and safety are of major importance in health policy and the requirement of homologous blood transfusion is also relevant. At the current price of aprotinin, approximately $£ 75$ (120 euros) per patient was spent on each operation. The price of 1.8 fewer units of blood (approximately $£ 120$ (190 euros)), led to a mean saving of $£ 45$ (70 euros) per patient. This should be compared with the use of erythropoietin which, in a study by Faris, Ritter and Abels, ${ }^{18}$ resulted in a reduction of transfusion of $37 \%$ and cost $£ 1500$ (2400 euros) per patient.
There has been one study on the effect of the postoperative use of aprotinin ${ }^{19}$ and further investigations will be undertaken.

No benefits in any form have been received or will be received from a commercial party related directly or indirectly to the subject of this article.

\section{References}

1. Kraut H, Frey EK, Werle E. Über die Inaktivierung des kallikneins:VI. Mitteilung über dieses kreislanfhotmon. Hoppe-Seyler's Z. Physiol Chem 1930;1-21.

2. Kunitz M, Northrop JH. Isolation from beef pancreas of crystalline trypsinogen, trypsin, a trypsin inhibitor and intibular trypsin compound. J Gen Physiol 1936;991-1007.

3. Royston D. High dose aprotinin therapy: a review of the first five years' experience. J Cardiothorac Vasc Anesth 1992;6:76-100.

4. Royston D, Bidstrup BP, Taylor KM, Sapsford RN. Effect of aprotinin on need for blood transfusion after repeat open-heart surgery. Lancet 1987;2:1289-91.

5. Lemmer JH, Stanford W, Bonney SL, et al. Aprotinin for coronary bypass operations: efficacy, safety, and influence on early saphenous vein graft patency: a multicenter, randomized, double-blind, placebocontrolled study. J Thorac Cardiovasc Surg 1994;107:543-51.

6. Capdevila X, Calvet Y, Biboulet P, et al. Aprotinin decreases blood loss and homologous transfusions in patients undergoing major orthopedic surgery. Anesthesiology 1998;88:50-7.

7. Murkin JM, Shannon NA, Bourne RB, et al. Aprotinin decreases blood loss in patients undergoing revision or bilateral total hip arthroplasty. Anesth Analg 1995;80:343-8.

8. Lentschener C, Benhamou D, Mercier JF, et al. Aprotinin reduces blood loss in patients undergoing elective liver resection. Anesth Analg 1997;84:875-81.

9. Lentschener C, Cottin P, Bouaziz H, et al. Reduction of blood loss and transfusion requirement by aprotinin in posterior lumbar spine fusion. Anesth Analg 1999;89:590-7.

10. Kasper SM, Schimidt J, Rütt J. Is aprotinin worth the risk in total hip replacement? Anesthesiology 1994;81:517-9.

11. Kasper SM, Elsner F, Hilgers D, Grond S, Rütt J. A retrospective study of the effects of small-dose aprotinin on blood loss and transfusion needs during total hip arthroplasty. Eur J Anaesthesiology 1998;15:66975 .

12. Langdown AJ, Field J, Grote J, Himayat H. Aprotinin (Trasylol) does not reduce bleeding in primary total hip arthroplasty. $J$ Arthroplasty 2000;15:1009-12.

13. Wollinsky KH, Mehrkens HH, Freytag T, Geiger P, Weindler M. Does aprotinin lessen intraoperative blood loss? Anästhesiol Intensivmed Notfallmed Schmerzther 1991;26:208-10.

14. Utada K, Matayoshi Y, Sumi C, et al. Aprotinin 2 million KIU reduces perioperative blood loss in patients undergoing primary total hip replacement. Masui 1997;46:77-82.

15. Janssens M, Joris J, David JL, Lemaire R, Lamy M. High dose aprotinin reduces blood loss in patients undergoing total hip replacement surgery. Anesthesiology 1994;80:23-9.

16. Murkin JM, Haig GM, Beer KJ, et al. Aprotinin decreases exposure to allogeneic blood during primary unilateral total hip replacement. $J$ Bone Joint Surg [Am] 2000;82-A:675-84.

17. Hayes A, Murphy DB, McCaroll M. The efficacy of single-dose aprotinin 2 million KIU in reducing blood loss and its impact on the incidence of deep venous thrombosis in patients undergoing total hip replacement surgery. J Clin Anesth 1996;8:357-60.

18. Faris PM, Ritter MA, Abels RI. The effects of recombinant human erythropoietin on perioperative transfusion requirements in patients having a major orthopaedic operation: the American Erythropoietin Group. J Bone Joint Surg [Am] 1996;78-A:62-72.

19. Cicek S, Demirkilic U, Ozal E, et al. Postoperative use of aprotinin in cardiac operations: an alternative to its prophylactic use. J Thorac Cardiovasc Surg 1996;112:1462-7. 